\title{
DESEASONALISED FORECASTING MODEL OF RAINFALL DISTRIBUTION USING FUZZY TIME SERIES
}

\author{
${ }^{1}$ Mahmod Othman \& ${ }^{2}$ Siti Nor Fathihah Azahari \\ ${ }^{1}$ Universiti Teknologi PETRONAS, Malaysia \\ ${ }^{2}$ Universiti Teknologi MARA, Malaysia \\ mahmod.othman@petronas.com.my
}

\begin{abstract}
Flood is a frequent occurrence which has a high calamity impact on human lifestyle, environment and economics. Although, there are various methods in the vast literature to predict rainfall distributions so as to prevent flood occurrences, the accuracy of these methods still remain a huge concern. Therefore, this study explores the application of the fuzzy time series method in order to obtain more accurate rainfall distribution predictions. Data for the study were collected from the Drainage and Irrigation Department Perlis (DID) of Malaysia. The data were analysed and validated using the mean square error (MSE) and the root mean squared error (RMSE). The result of the validation was compared with selected results in previous methods. The validation analysis depicts that this method has a higher forecasting accuracy than the previous methods.
\end{abstract}

Keywords: fuzzy time series, rainfall distribution, deseasonalising, rainfall forecasting.

\section{INTRODUCTION}

Unforeseen heavy rainfall can cause untold disaster which can affect both human and nonhuman existence on earth. Although, accurate prediction can avert this huge disaster, is still remains a big issue among researchers (Hung, Babel, Weesakul \& Tripathi, 2008; Zaw \& Thinn, 2009). Many studies in the vast literature have tackled this concern for accurate prediction which has produced various forecasting models. For instance, Yu, Chen and Chen (2000) proposed a model of rainfall forecasting based on the application of gray and fuzzy methods by using the fuzzy goal regression method as the model parameters. Likewise, Xiong, Shamseldin and O'Connor (2001) developed 
non-liner combination forecasts of rainfall-runoff models based on the firstorder Takagi-Sugeno fuzzy system. Later, Hung et al., (2008)implemented the artificial neural network (ANN) model by using 4 years of hourly data from 75 rain gauge stations in Bangkok to develop a rainfall forecasting model. ANN has solved many problems of application such as prediction, intelligent system and classification (Hasan, Quo \& Shamsuddin, 2012). Similarly, Wu, Chau and Fan (2010) proposed a modular artificial neural networks prediction for a rainfall time series model with the combination of data-pre-processing techniques. El-Shafie, El-Mazoghi, Shehata and Taha (2011) presented the dynamic neural network with multi-layer perceptron neural network (MLP$\mathrm{NN}$ ), the radial basis function neural network (RBFNN), and the input delay neural network (IDNN) model to predict rainfall distribution in the Klang River Basin. Additionally, Venkata Ramana, Krishna, Kumar and Pandey (2013) used artificial neural network (ANN) with the wavelet technique to develop a rainfall prediction distribution model. Despite these prediction models in the vast literature, there is still a growing concern for a more precise and high accurate model to forecast and predict rainfall distributions and patterns (Bennett, Robertson, Ward, Hapuarachchi \& Wang, 2016).

An alternative approach by Song and Chissom (1993a) developed the theory of fuzzy time series which was an improvement on the traditional time series methods of first-order time-invariant fuzzy time series and the first order time-variant fuzzy time series (Chen \& Hsu, 2004; Dani \& Sharma, 2013; Jeng-Ren, Shyi-Ming \& Chia-Hoang, 1998). Generally, the fuzzy time series concept explains that

$$
Z_{i}=Z_{i-1}^{\circ} R
$$

where;

$Z_{i-1}=$ fuzzified data of year $i-1$ represented by a fuzzy set,

$Z_{i} \quad=$ fuzzified data of year $i$ represented by a fuzzy set,

$\circ=$ max-min composition operator,

$R \quad=$ fuzzy relation formed by the fuzzified data of the fuzzy time series.

However, there are some weaknesses in the fuzzy time series method of Song and Chissom (1993a). Based on Eq. (1), the fuzzy relation $R$ needs a long time of calculation to be derived. Furthermore, it also affects the computation time of the max-min composition operation of Eq. (1) (Chen, 1996; Chen \& Hsu, 2004; Jeng-Ren et al., 1998). 
Nevertheless, there have been many previous studies that implemented this same concept as prediction models. For example, Li and Cheng (2007), Chen and Hsu (2004), and Jeng-Ren et al., (1998) had applied the fuzzy time series models in their studies to forecast the students' enrolment the University of Alabama. These three researchers had shown different improvement in several calculations and steps of the Song and Chissom (199a) fuzzy time series model to produce a more accurate result of forecasting. Egrioglu (2012) proposed the time-invariant fuzzy time series forecasting method which is based on genetic algorithm on membership value prediction. Tsaur and Kuo (2011) adopted the fuzzy time series model to forecast tourists' demand in Taiwan while Chen and Hwang (2000) applied the fuzzy time series model in forecasting temperature in their research. Meanwhile, Dani and Sharma (2013) introduced the fuzzy time series model to forecast rainfall in Ambikapur, Chhattisgarh by using 18 years of total monsoon rainfall data. However, the accurateness was still vague because of the large value of the Mean Square Error (MSE) in evaluating the model. A majority of other similar previous studies did not make use of the seasonalised components that existed in historical data, whereas this is vital in order to reduce error and improve the accuracy of forecasting. Besides, there are very limited applications of fuzzy time series models in forecasting rainfall distribution. Therefore, this study is proposing a forecast rainfall distribution model based on the first order and time-variant methods using deseasonalising rainfall data.

In the ubsequent sections, the basic concept of fuzzy time series and the definition of deseasonalising are explained in detail. Then, the methodology of the fuzzy time series model of rainfall forecasting is discussed. Next, the result and discussion of this study is highlighted followed by the conclusion that is presented in the last section.

\section{Basic Concept of Fuzzy Time Series}

The definition of fuzzy time series that was proposed by Song and Chissom (1993b) was based on fuzzy sets. Let $U$ be the universe of discourse, $U=\left\{\mathrm{u}_{1}\right.$, $\mathrm{u}_{2} \ldots \mathrm{u}_{\mathrm{n}}$ \} and let $M$ be a fuzzy set in the universe of discourse $U$ to be defined as follows:

$$
M=\frac{f_{M}\left(U_{1}\right)}{U_{1}}+\frac{f_{M}\left(U_{2}\right)}{U_{2}}+\cdots+\frac{f_{M}\left(U_{n}\right)}{U_{n}},
$$


where:

$$
\begin{aligned}
f_{M}= & \text { the membership function of } M, f_{M}: U \text { à }[0,1], \text { and } \\
f_{M}\left(u_{l}\right)= & \text { the grade of membership of } u_{i} \text { in the fuzzy set } M, f_{M}\left(u_{l}\right) \in[0,1], \\
& \text { and } 1 \leq i \leq \mathrm{n} .
\end{aligned}
$$

Let $X_{j}(t)(t=\ldots, 0,1,2, \ldots)$ be the universe of discourse and be the subset of $S$, let fuzzy set $f_{j}(t)(j=1,2, \ldots)$ be defined in $X_{j}(t)$. Let $W(t)$ be a collection of $w_{i}(\mathrm{t})(\mathrm{i}=1,2, \ldots)$. Then, $W(t)$ is called a fuzzy time series of $X_{j}(t)(t=\ldots, 0,1,2, \ldots)$. If $W(t)$ is caused by $W(t-1)$, denoted by $W(t-1)$ à $W(t)$, then this relationship can be represented by $W(t)=W(t-1)^{\circ} R(t, t-1)$, where the symbol "ow denotes the Max-Min composition operator; $R(t, t-1)$ is a fuzzy relation between $W(t)$ and $W(t-1)$ and is called the firstorder model of $W(t)$. Let $W(t)$ be a fuzzy time series and let $R(t$, $t-1)$ be a first-order model of $W(t)$. If $R(t, t-1)=R(t-1, t-2)$ for any time $t$, then $W(t)$ is called a time-variant fuzzy time series. If $R(t, t-1)$ is dependent on time $\mathrm{t}$, then $W(t)$ is called a timevariant fuzzy time series.

\section{Definition of Deseasonalising}

The actual Perlis rainfall distribution data that were collected from the Drainage and Irrigation Department were processed by analysing the presence of a seasonal component. The deseasonalising was implemented on the historical data to identify the existence of the seasonal component. This analysis approach was to remove the seasonal component of the data prior to analysis which was based on the Zuur and Pierce (2004) suggestion. In Lazim (2011), seasonal component, also known as seasonal variation, has the characteristic of regular fluctuation occurring within a specific period of time which can be within a day, a week, a month, a year or others durations. The fluctuation was repeated in the following periods with the same regulatory pattern. There were two methods of identifying the seasonal component in the data:

1. By calculating seasonal ratios or seasonal indices.

2. Through methods of seasonal differencing.

However, in this study, only one method was used which was the calculation of seasonal ratios or seasonal indices, and deseasonalising of data was done by assuming that an additive effect occurred in the graph. Deseasonalising is the process of removing the seasonal effect from the data series (Jones, 
Evans, Lipson, \& ClassPas, 2008; Lazim, 2011). Therefore, deseasonalising by additive effect was applied to the rainfall data. In fact, the additive effect was used because the components of the series interacted in an additive manner where the absolute sizes of the seasonal variation were independent of each other.

\section{METHODOLOGY}

\section{Rainfall Forecasting Based on Deseasonalising Fuzzy Time Series}

This study proposed the use of the fuzzy time series for the deseasonalised rainfall forecasting model of the rainfall. The methodology of forecasting rainfall was based on three phases. Figure 1 shows the flowchart of rainfall forecasting procedure of this study.

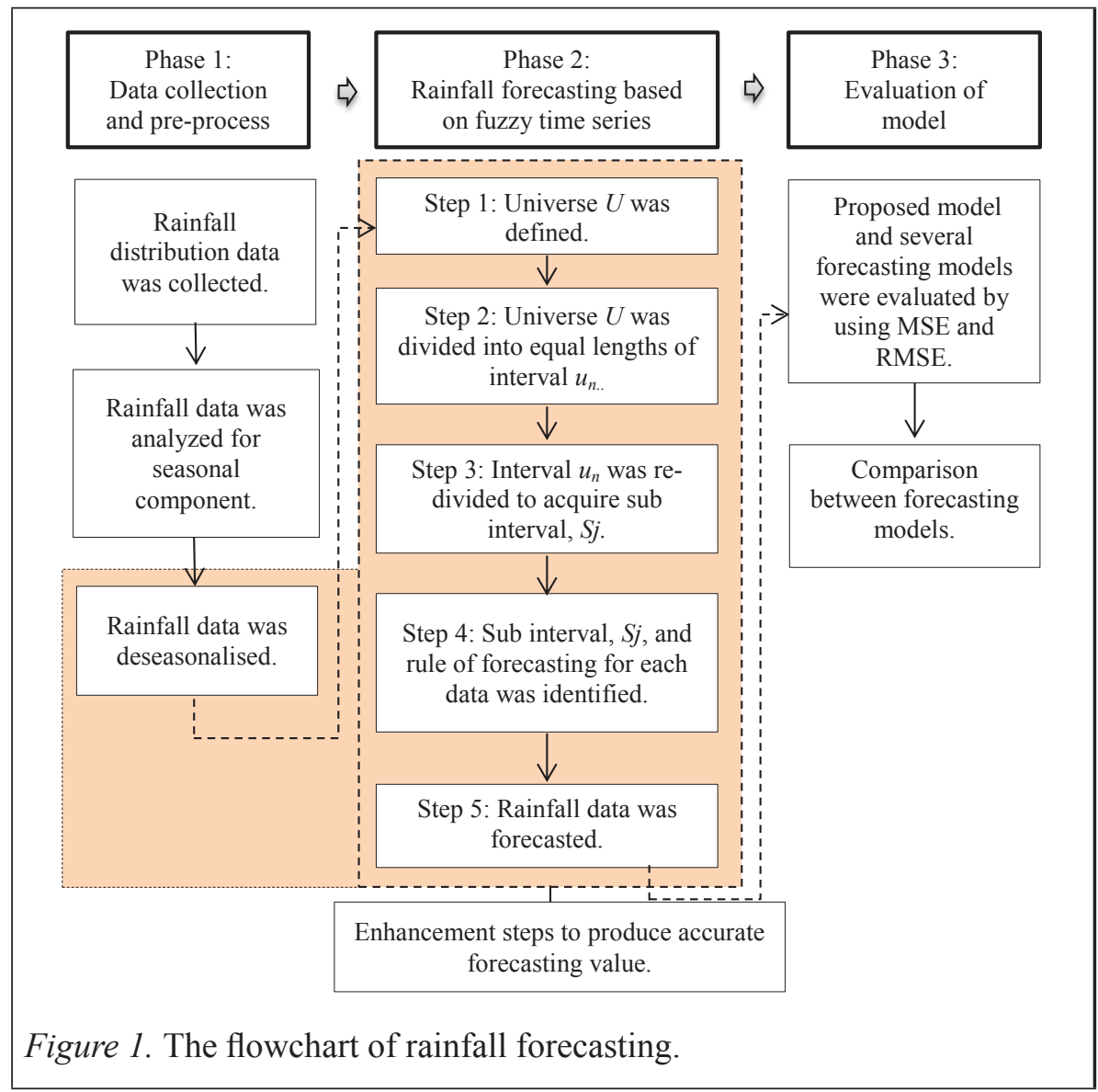


The process of forecasting rainfall consists of three phases: Phase 1 was data collection and pre-process. Phase 2 was rainfall forecasting model based on the fuzzy time series concept where the anhanced forecasting steps were used to improve the accuracy of the prediction model. Phase 3 shows the evaluation of the forecasting model. The proposed model was compared with the Dani and Sharma (2013) Model and the Single Exponential Model to identify which one was the best forecasting model. Detailed explanations are discussed as follows:

\section{Phase 1: Data Collection and Processing}

The historical data of rainfall distribution in millimeter $(\mathrm{mm})$ from 14 rainfall gauge stations in Perlis were collected from the Department of Irrigation and Drainage (DID). About 168 rainfall distribution data had been recorded starting from January 2000 until December 2013. The data were processed through the seasonal component analysis.

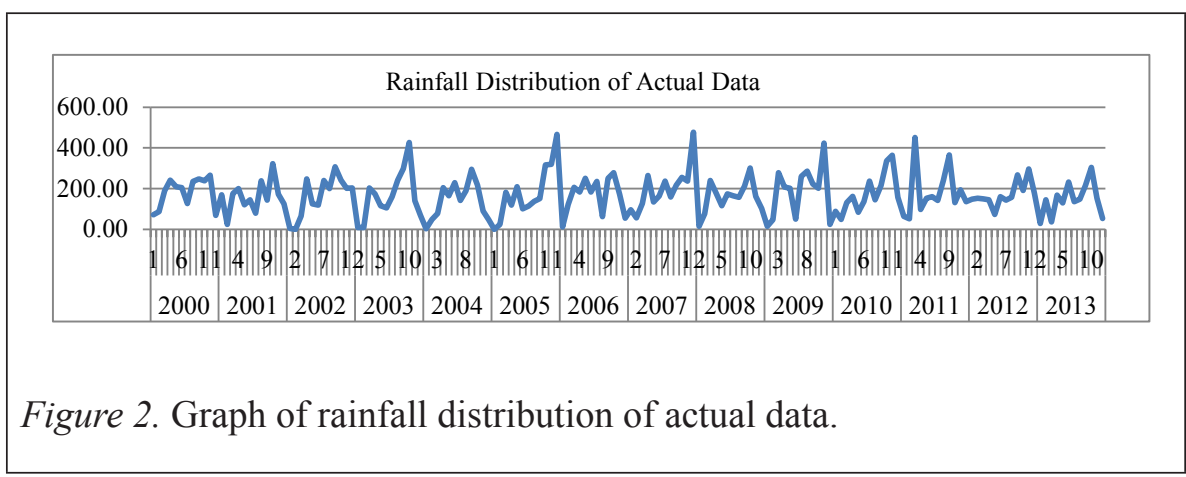

Figure 2 shows the scatter graph of rainfall distribution of the actual data in Perlis considered in this study. The seasonal component in the historical rainfall data was spotted based on the fluctuation on the graph which occurred yearly. Therefore, deseasonalising of data was done to remove the seasonal component. The steps of deseasonalising were as follows:

Step 1: Calculate the moving total of rainfall data.

Step 2: Determine centered moving totals and centered moving average.

Step 3: Calculate unadjusted seasonal indices.

Step 4: Adjust the seasonal indices.

Step 5: Remove the seasonal component based on the additive assumption method. 
Table 1 presents the sample rainfall distribution data in Perlis from January until December 2000 that was taken from the whole rainfall distribution data (January 2000 - December 2013) to demonstrate the deseasonalising. The first column of the table includes the year and month of rainfall distribution. The second column is the actual data of rainfall distribution in millimeter $(\mathrm{mm})$ while the third column is the new data of rainfall distribution in millimeter $(\mathrm{mm})$ after the deseasonalising process.

Table 1

The Sample of Rainfall Distribution Data

\begin{tabular}{cccc}
\hline Year/Month & $\begin{array}{c}\text { Actual rainfall data } \\
(\mathrm{mm})\end{array}$ & $\begin{array}{c}\text { Deseasonalising rainfall } \\
\text { data }(\mathrm{mm})\end{array}$ & Sub interval, $j \mathrm{j}$ \\
\hline $2000 / 01$ & 71.47 & 71.17 & $\mathrm{~S} 4$ \\
$2000 / 02$ & 87.43 & 87.07 & $\mathrm{~S} 5$ \\
$2000 / 03$ & 189.97 & 188.94 & $\mathrm{~S} 12$ \\
$2000 / 04$ & 241.27 & 240.18 & $\mathrm{~S} 16$ \\
$2000 / 05$ & 209.10 & 208.24 & $\mathrm{~S} 13$ \\
$2000 / 06$ & 204.47 & 203.56 & $\mathrm{~S} 13$ \\
$2000 / 07$ & 127.27 & 126.25 & $\mathrm{~S} 7$ \\
$2000 / 08$ & 234.98 & 233.87 & $\mathrm{~S} 15$ \\
$2000 / 09$ & 247.23 & 245.78 & $\mathrm{~S} 16$ \\
$2000 / 10$ & 239.40 & 237.81 & $\mathrm{~S} 15$ \\
$2000 / 11$ & 266.83 & 265.47 & $\mathrm{~S} 16$ \\
$2000 / 12$ & 69.67 & 68.76 & $\mathrm{~S} 4$ \\
\hline
\end{tabular}

\section{Phase 2: Forecasting Rainfall Distribution Based on Fuzzy Time Series}

Based on Figure 1, the next phase of the methodology is Phase 2. Detailed explanation of Phase 2 is presented in the following steps:

Step 1: Define the universe $U$.

Based on the rainfall distribution data, the universe $U$ was defined by identifying the highest reading data and the lowest reading data. Since, the lowest reading in the historical rainfall data was $0.00 \mathrm{~mm}$ and the highest reading data was $480.0 \mathrm{~mm}$, the universe $U=[0,480]$. 
Step 2: Determine the intervals of $u_{n}$.

The universe $U$ was divided into eight equidistant intervals: $u_{1}, u_{2}, u_{3}, u_{4}, u_{5}$, $u_{6}, u_{7}, u_{8}$. The length of each interval was 60 . Table 2 shows the result of the division.

Table 2.

The Equal Length Interval

\begin{tabular}{lcccccccc}
\hline Intervals & $u_{1}$ & $u_{2}$ & $u_{3}$ & $u_{4}$ & $u_{5}$ & $u_{6}$ & $u_{7}$ & $u_{8}$ \\
\hline Division of & {$[0,60]$} & {$[60,120]$} & {$[120,180]$} & {$[180$,} & {$[240$,} & {$[300$,} & {$[360$,} & {$[420$,} \\
Universe $\boldsymbol{U}$ & & & & $240]$ & $300]$ & $360]$ & $420]$ & $480]$ \\
\hline
\end{tabular}

Table 2 depicts the equal length interval. The first row is the interval of $u_{l}$, $u_{8}$, .The second row is the division of the universe $U$, starting from $[0,60]$ to $[420,480$

Step 3: Re-divide interval $u_{n}$ to acquire sub interval, $S j$.

In this step interval $u_{n}$ was re-divided to obtain the sub interval $\mathrm{Sj}$. The results of the division are presented in Tables 3 and 4 .

Table 3.

The Frequency of Rainfall Distribution (mm)

\begin{tabular}{lllllllll}
\hline Intervals, $u_{n}$ & $u_{1}$ & $u_{2}$ & $u_{3}$ & $u_{4}$ & $u_{5}$ & $u_{6}$ & $u_{7}$ & $u_{8}$ \\
\hline Frequency of rainfall distribution $(\mathrm{mm})$ & 23 & 23 & 52 & 37 & 19 & 7 & 2 & 5 \\
Rank & $3^{\text {rd }}$ & $3^{\text {rd }}$ & $1^{\text {st }}$ & $2^{\text {nd }}$ & $4^{\text {th }}$ & $5^{\text {th }}$ & $7^{\text {th }}$ & $6^{\text {th }}$ \\
Divide into & 3 & 3 & 5 & 2 & 4 & - & - & - \\
\hline
\end{tabular}

Table 3 shows the frequency of the rainfall distribution $(\mathrm{mm})$ based on the historical data. In Table 3, the first row is the interval of $u_{l}$, to $u_{8}$. The second row is the frequency of rainfall distribution based on the historical rainfall data. Meanwhile the third row was the 'Rank' that distinguishes between the highest and the lowest frequency rainfall distribution of the second row. The fourth row 'Divide Into' shows the division value of interval $u_{n}$. The 'Divide into' row of Table 3 is intertwined with Table 4. 
Table 4.

The Division of Interval $u_{n}$

\begin{tabular}{llllll}
\hline $\begin{array}{l}\text { Category of } \\
\text { rank }\end{array}$ & Highest $\left(1^{\text {st }}\right)$ & $\begin{array}{l}\text { Second } \\
\text { highest }\left(2^{\text {nd }}\right)\end{array}$ & $\begin{array}{l}\text { Third highest } \\
\left(3^{\text {rd }}\right)\end{array}$ & $\begin{array}{l}\text { Fourth } \\
\text { highest }\left(4^{\text {th }}\right)\end{array}$ & $\begin{array}{l}\text { Fifth highest and } \\
\text { so on }\left(5^{\text {th }}-n^{\text {th }}\right)\end{array}$ \\
\hline Divide into: & $\begin{array}{l}5 \text { sub- } \\
\text { intervals of }\end{array}$ & $\begin{array}{l}4 \text { sub- } \\
\text { intervals of }\end{array}$ & $\begin{array}{l}3 \text { sub- } \\
\text { intervals of }\end{array}$ & $\begin{array}{l}\text { 2 sub- } \\
\text { intervals of }\end{array}$ & $\begin{array}{l}\text { Intervals } \\
u_{n} \text { remains }\end{array}$ \\
& equal length & equal length & equal length & equal length & unchanged \\
\hline
\end{tabular}

Table 4 shows the division of interval $u_{n}$ based on the frequency of rainfall distribution in Table 3. The first row of Table 4 is the 'Category of rank' that classifies the highest, second highest, third highest, fourth highest or fifth highest of rainfall frequency while the second row of Table 4 is the'Divide into' which is the same as in the fourth row of Table 3. When the frequency of rainfall distribution $(\mathrm{mm})$ is the highest, then the interval $u_{n}$ is divided into 5 sub-intervals. The division then continues to the second, third and fourth highest category of rank respectively. Meanwhile when the frequency is categorised in the fifth rank and above, the interval $u_{n}$ remains unchanged. Hence, the new sub interval, $S j$, is obtained after re-dividing the interval $u_{n}$.

Table 5.

The Sub Intervals, Sj.

\begin{tabular}{llll}
\hline Sj & Range & Range & Sj \\
\hline S1 & $\mathrm{u} 1,1=[0,20]$ & $\mathrm{u} 1,2=[20,40]$ & $\mathrm{S} 2$ \\
S3 & $\mathrm{u} 1,3=[40,60]$ & $\mathrm{u} 2,1=[60,80]$ & $\mathrm{S} 4$ \\
$\mathrm{~S} 5$ & $\mathrm{u} 2,2=[80,100]$ & $\mathrm{u} 2,3=[100,120]$ & $\mathrm{S} 6$ \\
$\mathrm{~S} 7$ & $\mathrm{u} 3,1=[120,132]$ & $\mathrm{u} 3,2=[132,144]$ & $\mathrm{S} 8$ \\
$\mathrm{~S} 9$ & $\mathrm{u} 3,3=[144,156]$ & $\mathrm{u} 3,4=[156,168]$ & $\mathrm{S} 10$ \\
S11 & $\mathrm{u} 3,5=[168,180]$ & $\mathrm{u} 4,1=[180,195]$ & $\mathrm{S} 12$ \\
S13 & $\mathrm{u} 4,2=[195,210]$ & $\mathrm{u} 4,3=[210,225]$ & $\mathrm{S} 14$ \\
S15 & $\mathrm{u} 4,4=[225,240]$ & $\mathrm{u} 5=[240,270]$ & $\mathrm{S} 16$ \\
S17 & $\mathrm{u} 6=[270,300]$ & $\mathrm{u} 7=[300,360]$ & $\mathrm{S} 18$ \\
S19 & $\mathrm{u} 8=[360,420]$ & $\mathrm{u} 9=[420,480]$ & $\mathrm{S} 20$ \\
\hline
\end{tabular}

Table 5 presents the new sub interval, $S_{j}$, The intervals are increased from 8 intervals $u_{n}$ to 20 sub intervals, $S_{j}$. Each of the new sub interval, $S_{j}$, is defined as $\mathrm{S} 1, \mathrm{~S} 2, \mathrm{~S} 3 \ldots \mathrm{S} 20$. 
Step 4: Identify the sub interval, $S_{j}$, and the rule of forecasting for each data.

In this step, each of the rainfall data was matched to the appropriate subinterval. Next, the three types of forecasting rules being developed had to be categorised based on the following several equation:

$$
\begin{aligned}
& X_{t-1}-X_{t-2} \\
& \left(X_{t-1}-X_{t-2}\right)-\left(X_{t-2}-X_{t-3}\right)=+v e \\
& \left(X_{t-1}-X_{t-2}\right)-\left(X_{t-2}-X_{t-3}\right)=-v e
\end{aligned}
$$

where,

$X_{t} \quad=$ current rainfall prediction $(\mathrm{mm})$,

$X_{t-1} \quad=$ rainfall for a month before $(\mathrm{mm})$,

$X_{t-2} \quad=$ rainfall for two months before $(\mathrm{mm})$, and

$X_{t-3} \quad=$ rainfall for three months before $(\mathrm{mm})$.

Eq. (3),(4) and (5) consist of equations that describe how to select the type of forecasting rule in Table 6. In Eq. (3), the equation could only be applied to forecast rainfall for February and March 2000 because both these months did not have enough three months of rainfall in the previous data. Hence, these two months were classified in Rule 1. However, the forecasting rainfall data of January 2000, which was the first month of the rainfall data, was not predicted because there was no preceding rainfall data of that month.

In the meantime, Eq. (4) and (5), were applied based on the 3 months of the previous data. These three months of the previous data were needed for the subtraction procedure to predict the current rainfall data, $X_{t}$. If the subtraction between the three months' data obtained a positive value, the rainfall data was categorised in Rule 2, whilst the negative value of the subtraction was categorised in Rule 3. For instance, to identify the rule of forecasting in June 2000, the calculation is: (the difference of rainfall data in May 2000 and April 2000) minus (the difference of rainfall data in April 2000 and Mac 2000) is equal to negative values. Hence, the rule of forecasting for June 2000 is Rule 3. Eq. (4) and (5) were started to be applied on rainfall data starting from April 2000 to December 2013. 
Table 6.

The Rule of Forecasting

\begin{tabular}{cl}
\hline Type & Terms and Condition \\
\hline Rule 1 & This rule is valid only for the beginning of the data, which is February and \\
March 2000 . The previous two $(2)$ months of data are needed. Hence, if \\
the $\mid$ (the difference of current date and Zero $(0)$ data) $\left.\mid \times 2+X_{t}\right)$ is in the \\
sub-interval $S_{j}$, then the rainfall forecasting goes upward at the 0.75 -point \\
of this interval; if $\mid$ (the difference of current date and Zero $(0)$ data) $\mid / 2+$ \\
$X_{t}$ ) is in the sub-interval $S_{j}$, then the rainfall forecasting goes downward \\
at the 0.25 -point of this sub-interval. If neither is the case, the rainfall \\
forecast will be the middle value of the corresponding sub-interval $S_{j}$.
\end{tabular}

Rule 2 If $\left(\left|\left(X_{t-1}-X_{t-2}\right)-\left(X_{t-2}-X_{t-3}\right)\right| \times 2+X_{t}\right)$ falls in the corresponding interval $S_{j}$, then the rainfall forecasting goes upward at 0.75 -point of this interval; if $\left(\left|\left(X_{t-1}-X_{t-2}\right)-\left(X_{t-2}-X_{t-3}\right)\right| / 2+X_{t}\right)$ falls in the corresponding interval $S_{j}$, then the rainfall forecasting goes downward at the 0.25 -point of this interval. If neither is the case, the rainfall forecast will be the middle value of the corresponding interval $S_{j}$.

Rule 3 If ( $\left.\left|\left(X_{t-1}-X_{t-2}\right)-\left(X_{t-2}-X_{t-3}\right)\right| / 2+X_{t}\right)$ falls in the corresponding interval $S_{j}$, then the rainfall forecasting goes downward at the 0.25 -point of this interval; If $\left(\left|\left(X_{t-1}-X_{t-2}\right)-\left(X_{t-2}-X_{t-3}\right)\right| \times 2+X_{t}\right)$ falls in the corresponding interval $S_{j}$, then the rainfall forecasting goes upward at the 0.75 -point of this interval. If neither is the case, the rainfall forecast will be the middle value of the corresponding interval $S_{j}$.

Table 6 shows the rules of forecasting which are composed of three types of forecasting rules: Rule 1, Rule 2, and Rule 3. These three rules were applied to determine the trend of forecasting for each rainfall data depending on the rule's terms and conditions.

Step 5: Forecast the rainfall distribution.

When each of the rainfall data has been categorised by the rule of forecasting, forecasting the rainfall distribution can be started. The trend of forecasting for each of the rainfall data was identified based on the classification of the rules above. Table 8 shows the result of rainfall forecasting based on the fuzzy time series method. 


\section{Phase 3: Evaluate the forecasting models}

The evaluation of the forecasting model is the last phase of this study. It is very essential for a forecasting model to be evaluated in order to verify the effectiveness of the proposed model. There are various types of error measurements that can be used (Fuller, 2004), however, in this study the mean squared error (MSE) and the root mean squared error (RMSE) were employed. The MSE and the RMSE were used to verify the accuracy of the proposed model by calculating the error value between the actual data and the forecasting data (Lazim, 2011). The MSE and the RMSE were defined as follows:

$$
\begin{aligned}
& M S E=\frac{1}{n} \sum_{i=1}^{n}\left|\frac{\left(\text { Actual rainfall }_{i}-\text { Forecasted Rainfall }_{i}\right)^{2}}{\text { Actual rainfall }_{i}}\right| \\
& R M S E=\sqrt{\frac{\sum_{i=1}^{n} \mid\left(\text { Actual Rainfall }_{i}-\text { Forecasted Rainfall }_{i}\right)^{2} \mid}{n} .}
\end{aligned}
$$

The comparisons between several rainfall forecasting models were done. The tested forecasting models were Dani and Sharma's (2013) rainfall forecasting time series model, and the Single Exponential Smoothing model. The comparisons were done by referring to the result of the MSE and the RMSE for each model.

\section{RESULT AND DISCUSSION}

This section discusses the result of the deseasonalised forecasting model of rainfall distribution using the fuzzy time series. Table 8 shows part of the rainfall data from the actual data (January to December 2000). The results of Steps 4 and 5 from Phase 2 of the proposed model is also depicted in Table 8 .

Table 8

The Result of Rainfall Forecasting Based on Fuzzy Time Series

\begin{tabular}{cccc}
\hline $\begin{array}{c}\text { Deseasonalising rainfall } \\
\text { data in }(\mathrm{mm})\end{array}$ & $\begin{array}{c}\text { Rule of } \\
\text { forecasting }\end{array}$ & $\begin{array}{c}\text { Trend of } \\
\text { forecasting }\end{array}$ & $\begin{array}{c}\text { Forecast value of } \\
\text { rainfall }(\mathrm{mm})\end{array}$ \\
\hline 71.17 & & - & - \\
87.07 & 1 & Middle & 90 \\
188.94 & 1 & Middle & 187.5 \\
\hline
\end{tabular}




\begin{tabular}{cccc}
\hline $\begin{array}{c}\text { Deseasonalising rainfall } \\
\text { data in }(\mathrm{mm})\end{array}$ & $\begin{array}{c}\text { Rule of } \\
\text { forecasting }\end{array}$ & $\begin{array}{c}\text { Trend of } \\
\text { forecasting }\end{array}$ & $\begin{array}{c}\text { Forecast value of } \\
\text { rainfall }(\mathrm{mm})\end{array}$ \\
\hline 240.18 & 2 & Middle & 255 \\
208.24 & 3 & Middle & 202.5 \\
203.56 & 3 & Middle & 202.5 \\
126.25 & 2 & Middle & 126 \\
233.87 & 3 & Middle & 232.5 \\
245.78 & 2 & Middle & 255 \\
237.81 & 3 & Middle & 232.5 \\
265.47 & 3 & Middle & 255 \\
68.76 & 2 & Middle & 70 \\
\hline
\end{tabular}

in Table 8, the first column shows the deseasonalising rainfall distribution data. The second column shows the classification of the rules of forecasting as explained in Step 4 of Phase 2. Meanwhile, in the fourth column is the trend of forecasting that was identified based on the rule of forecasting. The last column is the forecasted value for rainfall distribution. The result of the evaluation for the forecasting models based on MSE and RMSE are summarized in Table 9. The proposed rainfall forecasting model of this study was compared to Dani and Sharma's (2013) Rainfall Forecasting Model, and the Single Exponantial Smoothing Forecasting model.

Table 9

The Comparison Between Forecasting Models

\begin{tabular}{clcc}
\hline No. & \multicolumn{1}{c}{ Model's name } & MSE & RMSE \\
\hline Model 1: & $\begin{array}{l}\text { Deseasonalising rainfall forecasting model } \\
\text { using fuzzy time series }\end{array}$ & 47.80 & 6.91 \\
Model 2 & $\begin{array}{l}\text { Dani and Sharma's (2013) forecasting } \\
\text { model }\end{array}$ & 129.58 & 11.38 \\
Model 3 & Single Exponential Smoothing $(\mathrm{a}=0.1)$ & 10006.3 & 100.33 \\
\hline
\end{tabular}

Table 9 describes the results of MSE and RMSE between the 3 types of rainfall forecasting models. Model 1 is the proposed forecasting model based on the fuzzy time series. Model 2 is the Dani and Sharma's (2013) Forecasting Model and Model 3 is the Single Exponential Smoothing $(\mathrm{a}=0.1)$ model. Based on the result in Table 9, the values of MSE and RMSE of Model 1 are 47.80 and 6.91 respectively. Meanwhile, Model 2 shows the values of MSE and RMSE as 129.58 and 11.38 subsequently. For Model 3, the MSE 
and RMSE results are 10,006.3 and 11.38, respectively. Therefore, Model 1 , which is the proposed rainfall forecasting model based on the fuzzy time series concept, shows the smallest MSE and RMSE and it is the best model offered for forecasting rainfall.

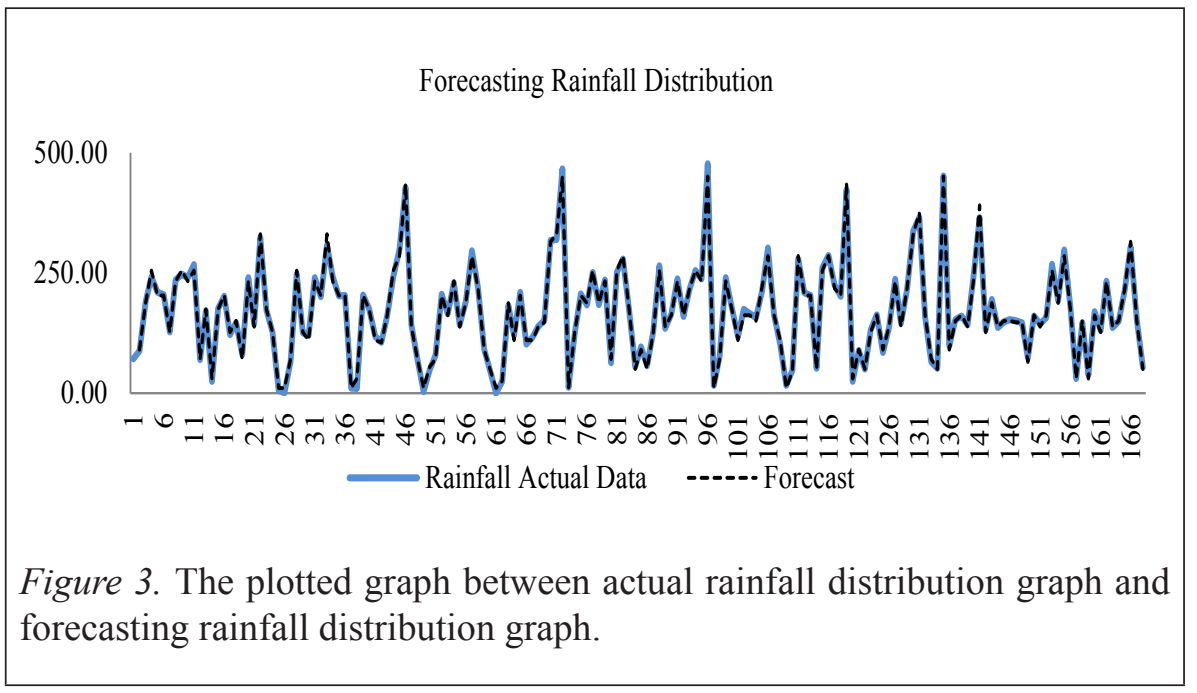

Figure 3 shows the plotted graph between the actual rainfall distribution and the forecasting rainfall distribution. Based on Figure 3, the forecasting rainfall distribution (dotted line) was found to be as nearly accurate as the actual rainfall distribution (blue line).

\section{CONCLUSION}

In conclusion, this study presented the application of deseasonalising and the fuzzy time series concept in forecasting rainfall distribution. The actual rainfall distribution data were pre-processed first by removing the seasonal component which is known as the deseasonalising process. Then, the forecasting of rainfall was done by implementing the fuzzy time series concept on the deseasonalising rainfall data. The model was evaluated by using two types of statistical criteria, namely the Mean Squared Error (MSE) and the Root Mean Squared Error (RMSE). Furthermore, the model result was compared with the two previous models, namely Dani and Sharma's (2013) Forecasting Model, and the Single Exponential Smoothing $(\mathrm{a}=0.1)$. Based on Table 8, the proposed model MSE and RMSE results were the smallest compared with the other results. Thus, this small value in MSE and RMSE 
suggests that the model is more effective and accurate compared to the other models. Therefore, the application of this forecast model should be able to provide more accurate predictions on rainfall distribution in order to avert future flood disaster by providing early warning information. This warning information will assist communities to adequately prepare themselves to face future flood disasters. For future work, this study can be further extended by applying the proposed method to deal with other forecasting problems.

\section{ACKNOWLEDGMENTS}

The study was funded by the "Long Term Research Grant (LRGS) (UUM/RIMPC/P-30)". A huge thank you to the Faculty of Computer and Mathematical Sciences, Universiti Teknologi MARA and Malaysia's Drainage and Irrigation of Department for providing the laboratory facilities, the information about the rainfall collected and the rainfall distribution data in completing the study.

\section{REFERENCES}

Bennett, J. C., Robertson, D. E., Ward, P. G. D., Hapuarachchi, H. A. P., \& Wang, Q. J. (2016). Calibrating hourly rainfall-runoff models with daily forcings for streamflow forecasting applications in meso-scale catchments. Environmental Modelling \& Software, 76, 20-36. doi: http://dx.doi.org/10.1016/j.envsoft.2015.11.006

Chen, S. M. (1996). Forecasting enrollments based on fuzzy time series. Fuzzy Sets and Systems, 81(3), 311-319. doi: http://dx.doi.org/10.1016/01650114(95)00220-0

Chen, S. M., \& Hsu, C. C. (2004). A new method to forecast enrollmentsusing fuzzy time series. International Journal of Applied Science and Engineering, 2(3), 234-244.

Chen, S. M., \& Hwang, J. R. (2000). Temperature prediction using fuzzy time series. IEEE Transactions on Systems, Man, and Cybernetics, Part B: Cybernetics, 30(2), 263-275. doi: 10.1109/3477.836375

Dani, S., \& Sharma, S. (2013). Forecasting rainfall of a region by using fuzzy time series. Asian Journal of Mathematics and Application, 2013, 10. 
Egrioglu, E. (2012). A new time-invariant fuzzy time series forecasting method based on genetic algorithm. Advances in Fuzzy Systems, 2012, 6. doi: $10.1155 / 2012 / 785709$

El-Shafie, A. H., El-Shafie, A. , El-Mazoghi, H. G., Shehata, A., \& Taha, M. R. (2011). Artificial neural network technique for rainfall forecasting applied to Alexandria, Egypt. 6(6), 1306-1316. doi: 10.5897/IJPS11.143

Fuller, S. R. (2004). Forecast verification: A practitioner's guide in atmospheric science. Edited by Ian T. Jolliffe and David B. Stephenson. Wiley, Chichester, 2003. xiv+240 pp. ISBN 047149759 2. Weather, 59(5), 132-132. doi: 10.1256/wea. 123.03

Hasan, S., Quo, T. S., \& Shamsuddin, S. M. (2012). Artificial fish swarm optmization for multilayer network learning in classification problems. Jornal of Information and Communication Technology, 11(1), 37-53.

Hung, N. Q., Babel, M. S., Weesakul, S., \& Tripathi, N. K. (2008). An artificial neural network model for rainfall forecasting in Bangkok, Thailand. Hydrology and Earth System Sciences Discussions, 5(1), 183-218.

Jeng-Ren, H., Shyi-Ming, C., \& Chia-Hoang, L. (1998). Handling forecasting problems using fuzzy time series. Fuzzy Sets and Systems, 100(1-3), 217-228. doi: http://dx.doi.org/10.1016/S0165-0114(97)00121-8

Jones, Evans, Lipson, T.N., \& ClassPas, C. (2008). Essential Futher Mathematic - Core Retrieved from http://www.cambridge.edu.au/ downloads/education/extra/209/PageProofs/Further\%20Maths\%20 TINCP/Core\%207.pdf

Lazim, M. A. (2011). Introduction business forecasting a practical approach (3rd ed.). Seri Kembangan, Selangor: University Publication Center (UPENA), UiTM.

Li, S.T., \& Cheng, Y.C. (2007). Deterministic fuzzy time series model for forecasting enrollments. Computers and Mathematics with Applications, 53(12), 1904-1920. doi: 10.1016/j.camwa.2006.03.036

Song, Q., \& Chissom, B. S. (1993a). Forecasting enrollments with fuzzy time series - Part I. Fuzzy Sets and Systems, 54(1), 1-9. doi: http://dx.doi. org/10.1016/0165-0114(93)90355-L 
Song, Q., \& Chissom, B. S. (1993b). Fuzzy time series and its models. Fuzzy Sets and Systems, 54(3), 269-277. doi: http://dx.doi.org/10.1016/01650114(93)90372-O

Tsaur, R.C., \& Kuo, T.C. (2011). The adaptive fuzzy time series model with an application to Taiwan's tourism demand. Expert Systems With Applications, 38(8), 9164. doi: 10.1016/j.eswa.2011.01.059

Venkata Ramana, R., Krishna, B., Kumar, S. R., \& Pandey, N. G. (2013). Monthly rainfall prediction using wavelet neural network analysis. Water Resources Management, 27(10), 3697-3711. doi: 10.1007/ s11269-013-0374-4

Wu, C. L., Chau, K. W., \& Fan, C. (2010). Prediction of rainfall time series using modular artificial neural networks coupled with datapreprocessing techniques. Journal of Hydrology, 389(1-2), 146-167. doi: http://dx.doi.org/10.1016/j.jhydrol.2010.05.040

Xiong, L., Shamseldin, A. Y., \& O'Connor, K. M. (2001). A non-linear combination of the forecasts of rainfall-runoff models by the first-order Takagi-Sugeno fuzzy system. Journal of Hydrology, 245(1-4), 196217. doi: http://dx.doi.org/10.1016/S0022-1694(01)00349-3

Yu, P. S., Chen, C. J., \& Chen, S. J. (2000). Application of gray and fuzzy methods for rainfall forecasting. Journal of Hydrologic Engineering, 5(4), 339-345. doi: 10.1061/(ASCE)1084-0699(2000)5:4(339)

Zaw, W. T., \& Thinn, T. N. (2009). Modeling of rainfall prediction over Myanmar using polynomial regression. Paper presented at the Computer Engineering and Technology, 2009. ICCET '09. International Conference on.

Zuur, A. F., \& Pierce, G. J. (2004). Common trends in northeast Atlantic squid time series. Journal of Sea Research, 52(1), 57-72. doi: http://dx.doi. org/10.1016/j.seares.2003.08.008 